\title{
Oral BCG vaccine in Crohn's disease
}

\author{
W. R. BURNHAM ${ }^{1}$, J. E. LENNARD-JONES, P. HECKETSWEILER, \\ R. COLIN, AND Y. GEFFROY
}

From St Mark's Hospital, London, and Hôpital Charles-Nicolle, Rouen, France

SUMMARY In a randomised double-blind trial over one year oral BCG has been compared with a control preparation in the treatment of chronic Crohn's disease. Overall assessment scores deteriorated in nine of 22 patients taking $\mathrm{BCG}$, and 11 of 26 in the control group $(\mathrm{P}=0 \cdot 25)$; this deterioration was great enough to be regarded as a clinical relapse in three patients taking BCG and in seven taking the control preparation $(\mathrm{P}>0 \cdot 1)$. No significant benefit from oral $\mathrm{BCG}$ treatment has been demonstrated.

There is evidence that some patients with Crohn's disease are anergic. In an attempt to stimulate the immune response, Geffroy and his colleagues (Geffroy et al., 1977) used BCG to treat Crohn's disease and the results of their preliminary studies were sufficiently encouraging to justify a controlled trial. This paper reports a double-blind comparison of oral Pasteur BCG with placebo in treatment of chronic Crohn's disease with special reference to the prevention of relapse.

\section{Methods}

\section{SELECTION OF PATIENTS}

All patients were attending St Mark's Hospital, London, or the Hôpital Charles-Nicolle, Rouen, fulfilled published criteria for the diagnosis of Crohn's disease (Lennard-Jones, 1971), and gave informed consent. Of the 50 patients, 29 were diagnosed on clinical, radiological, and, where possible, biopsy evidence as having inactive or mildly active Crohn's disease. The remaining 21 patients had been treated by one or more resections of diseased intestine with pathological confirmation of the diagnosis, but in every case residual (including anal) or recurrent intestinal disease was known to be present. A previous trial had shown that these patients with chronic Crohn's disease, who were not receiving other treatment, were the most likely to relapse and were therefore most suitable for assessing the effectiveness of BCG (Multicentre Trial, 1977).

Patients were excluded from the trial if a struc'Present address: Department of Therapeutics, City Hospital,
Nottingham NG5 1PB.

Received for publication 24 August 1978 tural complication of Crohn's disease such as stenosis with obstruction or abscess formation was present, or if regular outpatient follow-up was impossible. As a precaution, all patients had a radiograph of the chest to exclude active pulmonary tuberculosis and electrophoresis of serum proteins to exclude hypogammaglobulinaemia (Mande, 1968).

\section{TREATMENT}

Current treatment with corticosteroids, azathioprine, sulphasalazine, or long-term antibacterial drugs excluded a patient from the trial. Deterioration of the disease so that any of these treatments was judged necessary constituted a failure of the trial treatment and the trial ended. Short-term treatment with an antibacterial drug for coincidental infection, nutritional supplements such as vitamins or iron, and symptomatic treatment such as antidiarrhoeal drugs, antispasmodics, or analgesics were permitted.

Patients were allocated randomly to receive Pasteur BCG (Immuno BCG-F), $75 \mathrm{mg} /$ ampoule, or $3 \%$ methyl cellulose, $5 \mathrm{ml} /$ ampoule, which closely resembled the active vaccine.

The ampoules were stored in a domestic refrigerator and patients were taught to add the contents of one to four ampoules to fruit juice immediately before taking the contents by mouth. The dose was taken in this manner weekly or monthly before breakfast as follows: one ampoule in the first week, two ampoules in the second week, four ampoules weekly for the next 24 weeks, four ampoules monthly for the next six months.

\section{OUT-PATIENT SUPERVISION}

All patients were seen regularly as outpatients; in London at intervals of one to two months, in Rouen at intervals of three to four months. Patients reported 
any untoward events by telephone and were seen within a short time if increased symptoms or possible side-effects of treatment occurred.

\section{ASSESSMENT OF RESULTS}

At each outpatient visit an assessment form, with a prearranged scoring system, was completed. Symptoms were scored as absent $(0)$, mild with no limitation of activities (1), moderate with some limitation of activities (2), or severe with considerable limitation of activities (3). Those recorded were the sense of well-being, atdominal pain, bowel frequency, and rectal bleeding. Physical signs included recent weight loss, pyrexia, the presence or absence of an abdominal mass, atdominal tenderness, anal lesion, enterocutaneous fistula, joint, eye, or mucocutaneous lesions. The total possible clinical score, including all symptoms and signs was 31 . Laboratory investigations including haemoglobin concentration, white cell count, ESR, and serum albumin were each scored from $0-2$ by prearranged values. The total possible score for abnormal laboratory tests was 8 .

A barium radiograph was performed whenever possible at the beginning and end of the trial. Changes were assessed without knowledge of the treatment given and graded as marked improvement $(+2)$, no change or no comparison (0), marked deterioration $(-2)$, with appropriate intermediate values.
The results of the clinical and laboratory scores for the month at the beginning and end of the trial were compared. The difference between the two scores and the radiological score were summed as the net change during the treatment pericd.

Relapse of the disease was defined as a clinical deterioration of such severity that the clinician considered it necessary to stop the trial and give other treatment.

\section{Results}

Of the 50 patients who entered the trial, 27 in London and 23 in Rouen, 24 were allocated to BCG and 26 to placebo. The groups appearcd comparable as regards age, sex, length of history, previous resection ard anatomical distribution of disease, and initial clinical and laboratory scores (Tables 1 and 2).

\section{RELA P S E}

In each treatment group, 19 patients completed the trial period of one year. The disease relapsed in three patients taking BCG and seven taking the placebo $(P>0 \cdot 1)$. The relapses in the BCG group occurred at five, seven, and 12 months, and in the placebo group at one, two, $2 \frac{1}{2}$, four, 11,11 , and 12 months, $\left(\chi^{2}=1 \cdot 601, \mathrm{DF}=1, \mathrm{P}>0 \cdot 1, \log\right.$ rank test $)$. Radiological or surgical confirmation of the clinical deterioration was obtained in eight of 10 instances.

Table 1 Clinical details, assessment scores and outcome in patients given BCG

\begin{tabular}{|c|c|c|c|c|c|c|c|c|c|c|}
\hline \multicolumn{5}{|c|}{ Clinical details } & \multicolumn{6}{|c|}{ Assessment scores } \\
\hline \multirow[t]{2}{*}{ Patient } & \multirow[t]{2}{*}{ Age/sex } & \multirow{2}{*}{$\begin{array}{l}\text { Duration } \\
\text { (years) }\end{array}$} & \multirow[t]{2}{*}{ Distribution } & \multirow[t]{2}{*}{ Resection } & \multicolumn{2}{|c|}{ Clinical } & \multicolumn{2}{|c|}{ Laboratory } & \multirow[t]{2}{*}{$X R$} & \multirow[t]{2}{*}{ Outcome } \\
\hline & & & & & Init. & Final & Init. & Final & & \\
\hline $\mathbf{A H}$ & $31 \mathrm{M}$ & 0.5 & C & & 2 & 1 & 0 & 0 & 0 & \\
\hline $\mathbf{M L}$ & $29 \mathrm{~F}$ & 0.5 & C & & 0 & 0 & 1 & 0 & 0 & \\
\hline SM & $39 \mathrm{M}$ & 20 & IRA & I & 1 & 3 & 1 & 0 & +2 & \\
\hline EH & $22 \mathrm{~F}$ & 0.5 & C & & 1 & 1 & 1 & 1 & 0 & \\
\hline $\mathbf{A L}$ & $31 \mathrm{M}$ & 10 & $1 \mathrm{~A}$ & $\mathbf{I}+\mathbf{R H C}$ & 0 & 0 & 1 & 1 & 0 & \\
\hline $\mathrm{JC}$ & $42 M$ & 12 & ICA & & 0 & 0 & 0 & $i$ & 0 & \\
\hline PD & $24 \mathrm{~F}$ & 13 & IC & $\mathbf{I}+\mathbf{R H C}$ & 2 & 2 & 2 & 2 & 0 & \\
\hline FB & $23 \mathrm{~F}$ & 3 & IA & & 0 & 0 & 0 & 0 & -2 & \\
\hline JD & $64 \mathrm{M}$ & 10 & IA & RHC. I & 1 & 1 & 2 & $\mathbf{0}$ & 0 & \\
\hline JCD & $30 \mathrm{M}$ & 14 & I & RHC & 3 & 3 & 3 & 5 & 0 & \\
\hline $\mathbf{R P}$ & $50 \mathrm{M}$ & 5 & I & & 3 & 11 & 3 & 7 & -2 & $\mathbf{R}$ \\
\hline SL & $21 \mathrm{~F}$ & 2 & IC & & 0 & 6 & 1 & 8 & 0 & $\mathbf{R}$ \\
\hline CF & $51 \mathrm{M}$ & 40 & IC & RHC. I & 2 & 1 & 1 & 1 & 0 & \\
\hline PL & $25 \mathrm{M}$ & 7 & IC & IC & 0 & 0 & 0 & 0 & -2 & \\
\hline $\mathrm{BE}$ & $34 \mathrm{M}$ & 5 & IC & & 3 & 3 & 0 & 2 & +2 & \\
\hline $\mathbf{T F}$ & $34 \mathrm{M}$ & 5 & IA & & 4 & 4 & 1 & 1 & 0 & \\
\hline RC & $35 \mathrm{~F}$ & 13 & CA & & 3 & 8 & 1 & 0 & 0 & \\
\hline RL & $42 \mathrm{~F}$ & 16 & I & RHC & 6 & 2 & 2 & 2 & 0 & \\
\hline FB & $33 \mathbf{F}$ & 9 & C & & 6 & 2 & 3 & 1 & -2 & \\
\hline VG & $36 \mathrm{~F}$ & 2 & ICA & & 6 & 0 & 1 & 2 & +1 & \\
\hline MH & $35 \mathrm{~F}$ & 3 & ICA & & 2 & 1 & 2 & 3 & +2 & \\
\hline $\mathbf{K P}$ & $49 \mathrm{~F}$ & 11 & ICA & RHC & 8 & 10 & 1 & 3 & -2 & $\mathbf{R}$ \\
\hline LR & 27M & 10 & ICA & RHC & & & & & & SE \\
\hline IC & $29 \mathrm{M}$ & 2 & ICA & RHC. IRA & & & & & & SE \\
\hline Mean & 34.8 & $8 \cdot 9$ & & & $2 \cdot 4$ & $2 \cdot 7$ & $1 \cdot 2$ & 1.8 & -0.1 & \\
\hline
\end{tabular}

$\mathbf{I}=$ ileum. $\mathbf{C}=$ colon. $\mathbf{R}=$ rectum. $\mathbf{A}=$ anal. $\mathbf{R H C}=$ right hemicolectomy. $\mathbf{I R A}=$ colectomy and ileorectal anastomosis. $\mathbf{R}=$ relapse $\mathrm{SE}=$ withdrawn because of side-effects. 
Table 2 Clinical details, assessment scores and outcome in patients treated with placebo

\begin{tabular}{|c|c|c|c|c|c|c|c|c|c|c|}
\hline \multicolumn{5}{|c|}{ Clinical details } & \multicolumn{6}{|c|}{ Assessment scores } \\
\hline \multirow[t]{2}{*}{ Patient } & \multirow[t]{2}{*}{ Age/sex } & \multirow{2}{*}{$\begin{array}{c}\text { Duration } \\
\text { (years) }\end{array}$} & \multirow[t]{2}{*}{ Distribution } & \multirow[t]{2}{*}{ Resection } & \multicolumn{2}{|c|}{ Cinical } & \multicolumn{2}{|c|}{ Laboratory } & \multirow[t]{2}{*}{$X R$} & \multirow[t]{2}{*}{ Outcome } \\
\hline & & & & & Init. & Final & Init. & Final & & \\
\hline GB & $49 \mathrm{M}$ & 26 & IC & & 2 & 0 & 0 & 0 & 0 & \\
\hline JB & $24 M$ & 0.5 & $\mathrm{C}$ & & 3 & 0 & 5 & 0 & +2 & \\
\hline SS & $50 \mathrm{M}$ & 5 & I & & 0 & 0 & 1 & 2 & 0 & \\
\hline JH & $24 \mathrm{~F}$ & 2 & $\mathrm{CA}$ & & 0 & 0 & 0 & 0 & 0 & \\
\hline JH & $27 \mathrm{M}$ & 6 & I & & 0 & 0 & 0 & 0 & 0 & \\
\hline CG & $33 \mathrm{M}$ & 12 & IA & RHC. I & 0 & 0 & 0 & 0 & 0 & \\
\hline JD & $25 \mathrm{~F}$ & 0.5 & ICA & & 2 & 14 & 2 & 5 & -2 & $\mathbf{R}$ \\
\hline FF & $23 \mathrm{~F}$ & 12 & I & RHC & 3 & 9 & 0 & 2 & -1 & $\mathbf{R}$ \\
\hline AP & $24 \mathrm{M}$ & 6 & IA & I; I & 0 & 6 & 0 & 1 & -2 & $\mathbf{R}$ \\
\hline $\mathrm{CL}$ & $18 \mathrm{~F}$ & 1 & C & & 0 & 4 & 0 & 2 & -1 & $\mathbf{R}$ \\
\hline JB & $45 \mathrm{M}$ & 10 & CA & & 2 & 10 & 0 & 3 & -2 & $\mathbf{R}$ \\
\hline DH & $32 \mathrm{M}$ & 15 & ICA & RHC & 2 & 3 & 2 & 2 & 0 & \\
\hline WS & $42 \mathrm{M}$ & 21 & IC & IC; IC & 4 & 2 & 0 & 0 & 0 & \\
\hline $\mathbf{R H}$ & $17 \mathrm{M}$ & 3 & IC & & 0 & 0 & 0 & 0 & 0 & \\
\hline LC & $35 \mathrm{M}$ & 7 & IC & & 3 & 1 & 3 & 3 & -2 & \\
\hline $\mathrm{KJ}$ & $41 \mathrm{M}$ & 18 & ICA & RHC & 2 & 6 & 2 & 2 & 0 & \\
\hline DH & $46 \mathrm{M}$ & 2 & $\mathrm{C}$ & & 0 & 5 & 3 & 3 & -2 & \\
\hline JP & $20 \mathrm{~F}$ & 3 & ICA & IC; IC; IC & 2 & 4 & 1 & 1 & 0 & \\
\hline MR & $32 \mathrm{~F}$ & 6 & CA & & 2 & 1 & 0 & 0 & 0 & \\
\hline GC & $46 \mathrm{~F}$ & 16 & ICA & RHC & 1 & 0 & 0 & 0 & 0 & \\
\hline AC & $30 \mathrm{~F}$ & 12 & CA & IRA & 2 & 2 & 0 & 0 & 0 & \\
\hline PH & $28 \mathrm{~F}$ & 11 & ICA & RHC & 5 & 2 & 0 & 0 & -2 & \\
\hline JG & $45 \mathrm{M}$ & 2 & CA & & 2 & 1 & 0 & 0 & +2 & \\
\hline GT & $39 \mathrm{M}$ & 8 & ICA & & 1 & 7 & 5 & 5 & 0 & $\mathbf{R}$ \\
\hline $\mathrm{KMcB}$ & $21 \mathrm{~F}$ & 3 & IC & & 3 & 8 & 6 & 6 & -2 & $\mathbf{R}$ \\
\hline CB & $28 \mathrm{~F}$ & 3 & I & & 0 & 1 & 0 & 0 & 0 & \\
\hline Mean & $32 \cdot 5$ & $8 \cdot 1$ & & & $1 \cdot 6$ & $3 \cdot 3$ & 0.9 & $1 \cdot 4$ & -0.5 & \\
\hline
\end{tabular}

$\mathbf{I}=$ ileum. $\mathbf{C}=$ colon. $\mathbf{R}=$ rectum. $\mathbf{A}=$ anal. $\mathbf{R H C}=$ right hemicolectomy. $\mathbf{I R A}=$ colectomy and ileorectal anastomosis. $\mathbf{R}=$ relapse. $\mathrm{SE}=$ withdrawn because of side-effects.

\section{ASSESSMENT SCORES}

The clinical and laboratory assessment scores, and the radiological comparison, at the beginning and end of the trial are shown in Tables 1 and 2 . In both groups, overall scores tended to deteriorate slightly. The net change in total score between the beginning and end of the trial is shown in Fig. 1. This distribution, with a greater number of patients in the placebo group whose disease deteriorated, would have occurred frequently by chance $(P=0.25$, Mann-Whitney test).

\section{SIDE-EFFECTS}

Two patients on BCG were withdrawn because of side-effects. One developed diarrhoea and complained that the contents of the ampoules smelt of hydrogen sulphide (due to glutathione used as a preservative). He was subsequently able to resume treatment with BCG openly. The other patient developed nausea, vomiting, and diarrhoea which remitted when the vaccine was stopped and returned when it was reintroduced openly. No evidence of BCG infection was observed in any patient.

One patient in the placebo group developed diarrhoea which appeared to improve when the dose was reduced.

Analysis of all possible adverse effects that were reported showed no difference between the two groups.

\section{SERIAL TUBERCULIN TESTS}

Serial tests were performed by intradermal injection of $0.1 \mathrm{ml}$ of an ultrasonic lysate of $M$. tuberculosis standardised to contain $0.2 \mu \mathrm{g}$ protein in nine patients given BCG and 13 given placebo at $\mathrm{St}$ Mark's Hospital who completed one year in the trial. Eight of nine patients given $\mathrm{BCG}$ were initially tuberculin negative ( $<5 \mathrm{~mm}$ induration at 72 hours) and three gave a positive result at six and/or 12 months. Eight of 13 on placebo were initially tuberculin negative and two gave positive results at six and/or 12 months. No consistent trend was apparent in either group.

\section{Discussion}

Some studies have shown reduced lymphoblastic transformation and other test of cellular immune function in Crohn's disease but results have been conflicting (British Medical Journal, 1977). Two treatments for enhancing cellular immunity have been proposed but neither has yet been shown to be effective by controlled trial. Transfer factor restores to normal lymphocyte stimulation by phytohaemag- 


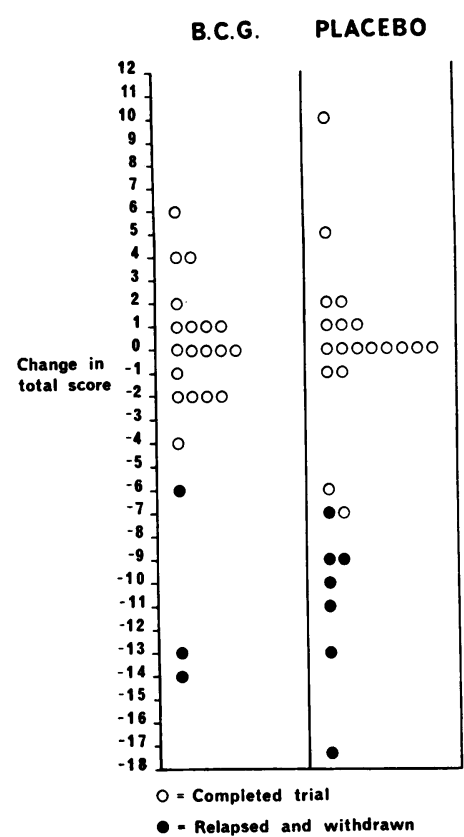

Figure The net change in assessment score between the beginning and end of the trial for each patient in the two treatment groups is shown. The patients whose disease did not relapse and who completed the trial period of one year are distinguished from those whose disease relapsed and who completed the trial earlier.

glutinin in Crohn's disease ( $\mathrm{Ng}$ and Vicary, 1976) and can cause positive conversion of the tuberculin test. Levamisole restores depressed leucocyte migration to normal (Segal et al., 1977) in Crohn's disease and may stimulate immunity.

The rationale of treating Crohn's disease by enhancing the immune response is thus based on an uncertain premise. Drugs with immunosuppressant properties may also be effective. Corticosteroids are of proven benefit in active Crohn's disease but not in reducing the relapse rate (Singleton 1977). Azathioprine does not appear beneficial in active Crohn's disease (Rhodes et al., 1971; Klein et al., 1974; Singleton, 1977) but in some studies the drug apparently reduces the relapse rate and may allow a maintenances dose of corticosteroids to be reduced (Willoughby et al., 1971; Rosenberg et al., 1975; O'Donoghue et al., 1978).

BCG has been used to enhance cellular immunity in oncology with some success. In leukaemia or solid tumours, the vaccine is administered by repeated scarification rather than by mouth. The oral route has been used for immunisation against tuberculosis (Mand :, 1968). This route was chosen for the present study because repeated scarification can be dis- figuring, preliminary studies suggested that the oral route may be effective and effectiveness may depend on locally induced immunity in the gut. Pasteur BCG, especially prepared for oral administration, was used because it had been used in the pilot studies and because its immunostimulant effect is particularly potent (Mackaness et al., 1973). The doses selected were arbitrary but in line with those used in early studies.

Patients with chronic inactive or mildly active disease were chosen for the trial because the use of a live vaccine precluded the use of corticosteroids or azathioprine. It was known that the risk of relapse was higher in these patients than in those treated surgically without evidence of residual disease (Multicentre Trial, 1977). In the event, one-fifth of the patients relapsed during the year.

The scoring system used for assessing results was designed before the introduction of the 'Crohn's disease activity index' (Best et al., 1976) which uses weighted criteria. The symptoms and signs used for assessment in the present system were the same as in the index, except for the inclusion of rectal bleeding and the omission of a factor for drug treatment of diarrhoea. The 'activity index' weights highly diarrhoea, abdominal pain, and sense of well-being. Scores in the present system appear lower than in the activity index because of the absence of weighting factors. The only laboratory value used in the 'activity index' is the haematocrit; our system includes haemoglobin, white cell count, ESR, and serum albumin. Scores associated with relapse tend to be relatively low because usually only a few of the many possible symptoms, signs, and laboratory values become abnormal.

Results of the trial showed a slight trend in favour of the active vaccine but very large numbers of patients would be needed to provide convincing evidence of any possible activity. The need to restrict other treatments, the possible dangers and the administrative difficulties suggest that oral BCG will not be clinically useful in chronic Crohn's disease. However, the treatment proved to be safe and well tolerated. Tuberculin conversion was inconstant. The use of BCG by other routes, in a different dose, or of other treatments to enhance immunity may warrant trial.

\section{References}

Best, W. R., Becktel, J. M., Singleton, J. W., and Kern, F. (1976). Development of a Crohn's disease activity index. Gastroenterology, 70, 439-444.

British Medical Journal (1977). Anergy in Crohn's diseasefact or fiction? (Leading Article) British Medical Journal, 1, 253-254. 
Geffroy, Y., Hecketsweiler, P., Colin, R., and Paillot, B. (1977). La thérapeutique immunostimulante de la maladie de Crohn. Annales de Gastroenterologie et d'Hépatologie, 13, 317-326.

Klein, M., Binder, H. J., Mitchell, M., Aaronson, R., and Spiro, H. (1974). Treatment of Crohn's disease with azathioprine; a controlled evaluation. Gastroenterology, 66, 916-922.

Lennard-Jones, J. E. (1971). Definition and diagnosis of Crohn's disease. In Regional Enteritis (Skandia International Symposia), pp. 105-112. Nordiska Bokhandelns Forlag: Stockholm.

Mackaness, G. B., Auclair, D. J., and Lagrange, P. H. (1973). Immunopotentiation with BCG. 1) Immune response to different strains and preparations. Journal of the National Cancer Institute, 51, 1655-1667.

Mande, R. (1968). BCG Vaccination. Dawsons: London.

Multicentre Trial (1977). Sulphasalazine in asymptomatic Crohn's disease. Gut, 18, 69-72.

$\mathrm{Ng}, \mathrm{R}$. P., and Vicary, F. R. (1976). Cell mediated immunity and transfer factor in Crohn's disease. British Medical
Journal, 2, 87-88.

O'Donoghue, D. P., Dawson, A. M., Powell-Tuck, J., Bown, R. L., and Lennard-Jones, J. E. (1978). Double-blind withdrawal trial of azathioprine as maintenance treatment for Crohn's disease. Lancet, 2, 955-957.

Rhodes, J., Bainton, D., Beck, P., and Campbell, H. (1971). Controlled trial of azathioprine in Crohn's disease. Lancet, 2, 1273-1276.

Rosenberg, J. L., Levin, B., Wall, A. J., and Kirsner, J. B. (1975). A controlled trial of azathioprine in Crohn's disease. American Journal of Digestive Diseases, 20, 721726.

Segal, A. W., Levi, A. J., and Loewi, G. (1977). Levamisole in the treatment of Crohn's disease. Lancet, 2, 382-384.

Singleton, J. W. (1977). National Cooperative Crohn's Disease Study: results of drug treatment. (Abstract). Gastroenterology, 72, 1133.

Willoughby, J. M. T., Kumar, P. J., Beckett, J. and Dawson, A. M. (1971). Controlled trial of azathioprine in Crohn's disease. Lancet, 2, 944-947. 